WP 1999-29

December 1999

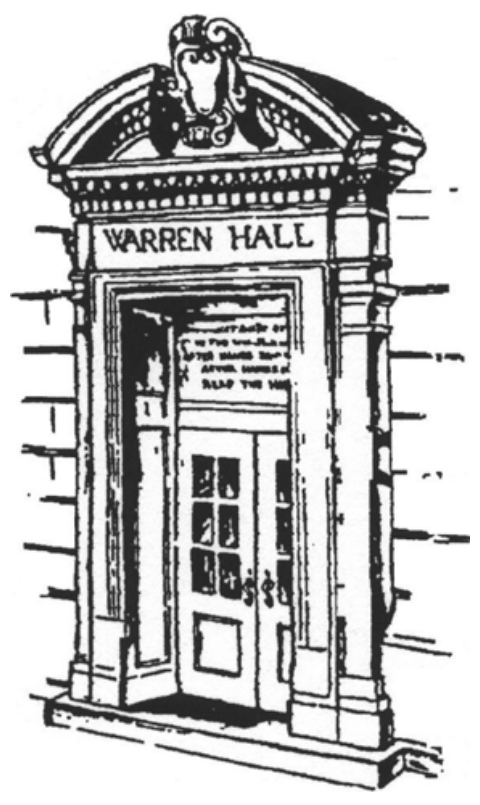

Working Paper

Department of Applied Economics and Management

Cornell University, Ithaca, New York 14853-7801 USA

\title{
Multifunctionality and Optimal Environmental Policies for Agriculture in an Open Economy
}

By Jeffrey M. Peterson, Richard N. Boisvert and Harry de Gorter 
It is the Policy of Cornell University actively to support equality of educational and employment opportunity. No person shall be denied admission to any educational program or activity or be denied employment on the basis of any legally prohibited discrimination involving, but not limited to, such factors as race, color, creed, religion, national or ethnic origin, sex, age or handicap. The University is committed to the maintenance of affirmative action programs which will assure the continuation of such equality of opportunity. 


\title{
Multifunctionality and Optimal Environmental Policies for Agriculture in an Open Economy
}

\author{
Jeffrey M. Peterson \\ Richard N. Boisvert \\ Harry de Gorter*
}

December 1999

This paper develops a general equilibrium framework to determine the optimal set of internalizing policies under multifunctionality and relates these policies to trade. When agriculture generates both amenity benefits and pollution, a welfare maximum can be achieved through a combination of a subsidy on agricultural land and a tax on polluting inputs, but the levels of these policies must be selected jointly. To illustrate this interaction, a set of stylized policy simulations of the aggregate U.S. agricultural sector is performed. The estimated optimal subsidy on farmland exceeds its social amenity value by approximately $50 \%$. If opened to international trade, small economies have no incentive to distort environmental policies away from their internalizing levels, but large economies will manipulate domestic policies in order to exploit terms of trade. As a large agricultural exporter, the U.S. could manipulate its environmental policy set to increase world agricultural prices by an estimated $9 \%$ over a base case of no environmental policy.

\footnotetext{
* The authors are Graduate Research Assistant, Professor, and Associate Professor, respectively in the Department of Agricultura 1, Resource, and Managerial Economics, Cornell University, Ithaca, NY.
} 


\section{Multifunctionality and Optimal Environmental Policies for Agriculture in an Open Economy}

Though agriculture has long been recognized as a polluter, it has also more recently been noted as a provider of non- market benefits. Examples of these public goods that are by-products of agriculture include landscape amenities, a habitat for wildlife, and the preservation of agrarian cultural heritage (Bohman et al., OECD 1997a,b). Though many of these benefits are difficult to define and measure, non-market valuation studies have found substantial non-market values for farmland in different regions around the world (Beasley et al.; Hackl and Pruckner; Lopez et al.). The notion of agriculture providing a set of non-market goods and bads as joint products with market goods has given rise to the term "multifunctionality" (Runge, 1998; Lindland; Nersten and Prestegard). Conceptually, a multifunctional agriculture means that the agricultural production process is a multioutput technology, where some outputs are privately traded commodities and others are public goods. This case differs from standard environmental models where some activity in the economy generates a single externality.

The realization that agriculture is multifunctional has important implications for policy making at both the domestic and international levels. In the domestic sphere, policies aimed at the various externalities from agriculture are typically legislated and administered independently. Likewise, the economics literature almost always examines externalities in isolation, either implicitly or explicitly assuming that other (potentially related) externalities are fixed or unimportant. If agriculture is multifunctional, the interrelationships among externalities implies that "compartmentalized" government programs may work at cross-purposes (Poe, 1997). For example, many governments use price supports in combination with acreage subsidies in an effort to internalize the positive externalities from agricultural production, but it has been shown that the level of these policies must affect the amount of agricultural pollution generated and 
vice-versa (Ollikainen). Jointness among externalities implies that policies to correct them must also be selected jointly, but the proper design of such a set of agro-environmental policies remains largely unexplored.

In the international arena, as evidenced by the recent controversy surrounding the agenda for the next round of WTO negotiations, the complexity of agricultural externalities will also make new trade agreements difficult to achieve (Blandford and Fulponi; Anderson and Hoekman; Runge 1999). Many countries have made known their fear that, without adequate safeguards, free trade will jeopardize the public good functions of agriculture. Trading partners who seek access to those markets, on the other hand, question whether so-called environmental safeguards may be trade distorting protectionism in disguise (ABARE, Bohman et al.).

High-cost agricultural producing countries with high levels of support, notably the EU, Norway, Switzerland, Japan, and South Korea, insist that subsidies on farm commodities are the most efficient way to secure public goods that are by-products of farm output. National food security and an authentic agricultural landscape, for example, cannot be produced separately from farm commodities (WTO, 1999a,b,c; Norwegian Royal Ministry of Agriculture). Further, reduced subsidies and freer trade would generate additional production in low-income and lowsupport countries; high-support countries have argued that such an expansion in those countries could damage the environment (because of deforestation and the lack of environmental regulations).

Lower cost producers would stand to gain considerably from reduced support in protected countries. These governments have argued that price supports as a way of obtaining agricultural public goods are neither optimal nor desirable. Such policies distort market incentives toward the intense use of polluting inputs, and there exist less-distorting policy instruments to achieve 
the same goal (WTO, 1998; Bohman et al.). Moreover, they argue, the weight of empirical evidence suggests that freer trade would improve environmental quality in both developed and developing nations, although even more could be gained if free trade were combined with environmental protection policies (e.g., Anderson, 1992a; Whalley). Yet the most fundamental concern is that, however high-minded the purpose of public-good-providing policies may be, those policies may be manipulated to distort terms of trade.

For the case of a single externality, the relationship between environmental policy and trade has been a subject of much recent study (Anderson, 1992b; Copeland; Krutilla; Beghin et al.; Schamel and de Gorter). This literature has revealed the potential for using an environmental policy as a tool to distort trade: A large importer, for example, may select lax environmental regulations in order to encourage domestic production, reduce the demand for imports, and lower prices to domestic consumers. However, the relationship between trade and a set of joint policies aimed at multiple externalities (i.e., the multifunctional case) has not yet been studied.

This paper develops a general equilibrium framework to determine the optimal set of internalizing policies under multifunctionality and relates these policies to trade. The model is based on an aggregate multioutput technology, where two basic factors (land and non-land inputs) produce two private commodities (agricultural and industrial goods) and two public goods (the positive and negative externalities from agriculture). Because the focus is on the agricultural sector, the model abstracts from marginal changes in industrial externalities. Production in the economy is cast in a modified Hecksher-Ohlin framework where agriculture generates two externalities.

The analysis identifies the interdependence among optimal environmental policies. In principle, a welfare maximum can be achieved through a combination of a subsidy on 
agricultural land and a tax on agricultural non-land inputs, but the levels of these policies must be selected jointly. In particular, if the pollution function for each acre is convex, a marginal acre of land reduces total pollution, and the optimal subsidy on an acre of farmland therefore exceeds the amenity value of that acre. Based on a set of stylized policy simulations of the aggregate U.S. agricultural sector, this interaction between policies appears to be empirically important; the estimated optimal subsidy for farmland is about 50\% larger than its amenity value.

The relationship between these joint environmental policies and trade is also characterized. Small economies have no incentive to distort environmental policies away from their internalizing levels, but large economies will manipulate domestic policies in order to exploit terms of trade. Consistent with observation, large importers such as Japan can improve domestic welfare by over-subsidizing public goods, while large exporters like the U.S. prefer strict regulations to limit pollution. Empirical simulations of U.S. agriculture suggest that environmental policies can be effective at distorting trade. If these policies were used to exploit terms of trade, the U.S. alone could increase world agricultural prices by an estimated $9 \%$ over a base case of no environmental policy.

The remainder of the paper is organized as follows. A theoretical section first describes the model economy and then derives optimal environmental policies for a closed economy, a small open economy, and a large open economy. To illustrate the theoretical relationships and explore their potential quantitative impacts, the next section simulates an empirical version of the model for the U.S. agricultural sector. The conclusions drawn from our findings and their implications for policy are examined in the final section. 


\section{The Model Economy}

Let $x$ and $y$ represent agricultural and non-agricultural goods, respectively. These two commodities can be produced from two basic factors, land $L$ and non-land inputs $Z$. In addition, the agricultural production process generates non-market amenities $a$ and emissions of pollution $e$. The technology set for aggregate production in this economy is:

$$
T=\left\{(x, y, a, e, L, Z) \in \mathfrak{R}_{+}^{6}:(L, Z) \text { can produce }(x, y, a, e)\right\}
$$

If there are no direct links between the agricultural and non-agricultural production processes, then a tradeoff between the output of the two commodities occurs only because inputs must be diverted away from one industry in order to increase production in the other. Assume the two technologies can be represented by the production functions:

$$
F_{x}\left(L_{x}, Z_{x}\right) \quad \text { and } \quad F_{y}\left(L_{y}, Z_{y}\right)
$$

where $L_{i}$ and $Z_{i}$ are the amount of land and other inputs allocated to the production of good $i$, respectively.

Let $L$ and $Z$ represent the endowment of land and non-land inputs, respectively, and assume the entire endowment of each factor is homogeneous in quality. Presuming non-wasteful allocations, production is subject to the feasibility conditions:

$$
\begin{aligned}
& L_{x}+L_{y}=L \\
& Z_{x}+Z_{y}=Z
\end{aligned}
$$

Each $F_{i}(\cdot)$ is strictly increasing, strictly concave, and exhibits constant returns to scale. By homogeneity, $F_{i}\left(L_{i}, Z_{i}\right)=L_{i} F_{i}\left(1, Z_{i} / L_{i}\right) \equiv L_{i} f_{i}\left(z_{i}\right)$, where $z_{i}$ represents the $Z_{i} / L_{i}$ ratio (per-acre input) and $f_{i}(\cdot)$ is the per-acre production function. 
Without loss of generality, aggregate emissions of agricultural pollution can be expressed as a function of the agricultural inputs $L_{x}$ and $Z_{x}: e=G\left(L_{x}, Z_{x}\right){ }^{1}$ If $L_{x}$ and $Z_{x}$ both double (thus keeping $z_{x}$ constant), total emissions must also double when land is of undifferentiated quality. Hence, $G(\cdot)$ is homogeneous of degree one. By the same argument as above, emissions may be equivalently expressed as $e=L_{x} g\left(z_{x}\right)$, where $g(\cdot)$ represents the amount of pollution generated per acre. Assume that $g$ is strictly increasing, strictly convex, and that $g(0)=0$. Under these conditions, pollution falls with marginal increases in the agricultural land base, i.e., $\partial e / \partial L_{x}<0 .^{2}$

The non-market amenities from agriculture, such as open space and a habitat for wildlife, depend only on the quantity of agricultural land. The extent to which pollution detracts from any of these amenities can be captured in consumers' preferences with respect to $e$. As above, homogenoeus land implies that the amenity function is homogeneous of degree one, or that each acre of land provides a fixed amount of amenity services. If we choose to measure these services so that each acre of farmland provides one unit of amenities, then $a=L_{x}{ }^{3}$

Consumers' preferences are represented by the aggregate utility function $u(x, y, a, e)$, where $u(\cdot)$ is strictly quasi-concave, strictly increasing in $x, y$, and $a$, and strictly decreasing in $e$.

\footnotetext{
${ }^{1}$ If emissions are some function of agricultural output; i.e., $e=h(x)$, pollution can also be expressed as $e=h\left(F_{x}\left(L_{x}\right.\right.$, $\left.\left.Z_{x}\right)\right)=G\left(L_{x}, Z_{x}\right)$.

${ }^{2}$ To verify, $\partial e / \partial L_{x}=g\left(z_{x}\right)+L_{x} g^{\prime}\left(z_{x}\right)\left(-Z_{x} / L_{x}^{2}\right)=g\left(z_{x}\right)-g^{\prime}\left(z_{x}\right) z_{x}$. The last expression has the same sign as $g\left(z_{x}\right) / z_{x}-$ $g^{\prime}\left(z_{x}\right)<0$, where the inequality follows from the Mean Value Theorem. Intuitively, an acre increase in $L_{x}$ produces two effects on $e$ : the extra pollution on the acre added, and the decrease in pollution on the acres previously in production that follows from a change in the input ratio $Z_{x} / L_{x}$. If pollution satisfies CRS, the change in the input ratio decreases pollution by $g^{\prime}(\cdot) z_{x}$; the net effect is always negative because "average pollution" $g / z_{x}$ must be less than "marginal pollution" $g^{\prime}$ if $g$ is convex (the opposite of the analogous relationships for a concave production function). More generally, if pollution is not necessarily CRS, the effect on total pollution from an increase in farmland depends on the heterogeneity of land; bringing an environmentally sensitive acre of land into production may increase total pollution. However, provided that the pollution function on every parcel of land is convex, the extra pollution from an extra acre is likely to be outweighed by the combined decrease in pollution on the acres already in production.

${ }^{3}$ Conceptually, there is a more general amenity function that relates the quantity of agricultural land to the amount of amenity services produced. Because of the obvious difficulties in measuring and observing amenity services per se, the valuation literature assumes that amenities are produced in proportion to the agricultural land base and attempts to estimate the value of amenities per acre (Poe, 1999).
} 
National income $I$ is the total payments received on the factors used in the two industries. Consumers use income to purchase $x$ and $y$, but cannot influence the levels of $a$ and $e$. Taking $y$ to be the numeraire and letting $p$ be the price of $x$, indirect utility is:

$$
\begin{aligned}
v(p, I, a, e)=\max & u(x, y, a, e) \\
\text { s.t. } \quad & p x+y \leq I, \quad(x, y) \in \mathfrak{R}^{2}+
\end{aligned}
$$

The function $v(\cdot)$ can be interpreted as social welfare for a given combination of price, income, and externalities. The solutions to the maximization problem $x(p, I, \cdot)$ and $y(p, I, \cdot)$ are the demands for agricultural and manufactured goods, respectively.

\section{Optimal Policies in a Closed Economy}

Because $a$ and $e$ are public goods, the market price system cannot internalize the marginal amenity benefits of agricultural land and the marginal cost of pollution, and producers will not choose the socially optimal factor allocation unless there is some policy intervention. Below, the optimal policies are determined using the following procedure: First, social welfare is derived as a function of the factors $L_{x}$ and $z_{x}$, and the welfare maximization problem is solved to determine the optimal allocation of the two factors. Second, the free market allocations of $L_{x}$ and $z_{x}$ are derived under an arbitrary policy scheme, and the optimal scheme is then chosen so that the free market and welfare maximizing allocations coincide.

Social welfare in this economy $v(\cdot)$ can be written as a function of $L_{x}$ and $z_{x}$, provided the utility function is properly restricted so that $x(\cdot)$ is monotonic in $p$. To verify this, note that monotonicity of demand implies a unique market clearing price $p$ for any amount of agricultural production. Further, profits are always zero due to cons tant returns to scale, and factor payments to households (national income $I$ ) must therefore equal total revenue from the two industries. 
Thus, $p$ and $I$ can be regarded as functions of $L_{x}$ and $z_{x}$ that are implicitly defined by the equations:

$$
\begin{aligned}
& x\left(p\left(L_{x}, z_{x}\right), I\left(L_{x}, z_{x}\right), \cdot\right)=L_{x} f_{x}\left(z_{x}\right) \\
& I\left(L_{x}, z_{x}\right)=p\left(L_{x}, z_{x}\right) L_{x} f_{x}\left(z_{x}\right)+\left(L-L_{x}\right) f_{y}\left(z_{y}\right)
\end{aligned}
$$

where $z_{y} \equiv Z_{y} / L_{y}=\left(Z-z_{x} L_{x}\right) /\left(L-L_{x}\right)$. The problem of maximizing social welfare in a closed economy can therefore be written:

$$
\begin{array}{cc}
\max & v\left(p\left(L_{x}, z_{x}\right), I\left(L_{x}, z_{x}\right), L_{x}, L_{x} g\left(z_{x}\right)\right) \\
& L_{x} \in[0, L], \quad z_{x} \in\left[0, Z / L_{x}\right]
\end{array}
$$

Under appropriate assumptions on $u(\cdot)$ and $F_{i}(\cdot)$, a solution to this problem cannot occur on the boundary of the constraint set. ${ }^{4}$ If a solution exists, it must satisfy the first-order conditions for an interior maximum:

$$
\begin{aligned}
& v_{p} p_{L}+v_{I} I_{L}+v_{a}+v_{e} g\left(z_{x}\right)=0 \\
& v_{p} p_{z}+v_{I} I_{z}+v_{e} L_{x} g^{\prime}\left(z_{x}\right)=0
\end{aligned}
$$

where subscripts denote derivatives. The Envelope Theorem applied to the consumer's utility maximization problem implies that $v_{I}=u_{y}, v_{a}=u_{a}$, and $v_{e}=u_{e} ; v_{p}=-x(p, I) v_{I}$ by Roy's Identity; and the first-order conditions for utility maximization require that $p=u_{x} / u_{y}$. Substituting these conditions, the derivatives of $I$ from (2), and the market clearing condition (1) into (4) and (5), one obtains the following equivalent conditions expressed in terms of the utility and production functions (demonstration in appendix):

$$
\frac{u_{x}}{u_{y}} f_{x}\left(z_{x}\right)-\left[f_{y}\left(z_{y}\right)-f_{y}^{\prime}\left(z_{y}\right)\left(z_{y}-z_{x}\right)\right]+\frac{u_{a}}{u_{y}}+\frac{u_{e}}{u_{y}} g\left(z_{x}\right)=0
$$

\footnotetext{
${ }^{4}$ More precisely, if marginal utilities and marginal products become infinite as their respective arguments approach zero, then there must be a positive allocation of both factors to both industries.
} 


$$
\frac{u_{x}}{u_{y}} f_{x}^{\prime}\left(z_{x}\right)-f_{y}^{\prime}\left(z_{y}\right)+\frac{u_{e}}{u_{y}} g^{\prime}\left(z_{x}\right)=0
$$

Each of these conditions requires the net marginal benefits of each factor to be zero. Equation (6) defines the optimal allocation of $L_{x}$. The first term is the marginal benefit of using land to produce $x$, the term in brackets is the marginal opportunity value of using land to produce $y, u_{a} / u_{y}$ is the marginal amenity benefit of land in agriculture, and the last term (note that $u_{e}<0$ ) is the marginal cost of pollution. Because each term has been divided by $u_{y}$, the benefits and costs are compared in terms of the numeraire. In equation (7), the optimal choice of $z_{x}$ is determined by setting to zero the sum of the marginal benefits of producing $x$, the marginal opportunity value in terms of $y$ production foregone, and marginal environmental cost.

Although each of the preceding equations describes the optimal allocation of one factor, they are collectively a simultaneous system in both variables $L_{x}$ appears in both equations through the expression for $\left.z_{x}\right)$. Letting $\left(L_{x}^{o}, z_{x}^{0}\right)$ represent the socially optimal allocation, simultaneity implies any shift in preferences that changes either $u_{a}$ or $u_{e}$ will induce a change in both $L_{x}^{o}$ and $z_{x}^{\circ}$.

Several types of policies have been proposed to internalize the environmental effects of agriculture. Consider four policy instruments that may be imposed jointly: a subsidy on agricultural output $\left(s_{x}\right)$, a subsidy on agricultural land $\left(s_{L}\right)$, a tax on agricultural input $\left(t_{z}\right)$, and a direct tax on pollution $\left(t_{e}\right){ }^{5}$ The policy problem is therefore to determine a policy scheme $s=$ $\left(s_{x}, s_{L}, t_{z}, t_{e}\right)$ that allows the socially optimal outcome to be decentralized through free markets.

\footnotetext{
${ }^{5}$ Because amenities are proportional to $L_{x}$, the subsidy on agricultural land is equivalent to a direct subsidy on amenities. All these policies that operate on prices are meant to represent a broader class of policy tools. Because there is an equivalent restriction on factor quantities for every tax, the input tax can also represent regulations that limit input use. Similarly, when land is initially taxed (as it is in most countries), the land subsidy is equivalent to policies that reduce property tax burdens or place controls on land use conversion.
} 
Given a set of policies $s$, a price $p$, and factor endowments $(L, Z)$, the "invisible hand" of competition will solve the revenue maximization problem (Dixit and Norman):

$$
\begin{gathered}
\max \left(p+s_{x}\right) L_{x} f_{x}\left(z_{x}\right)+s_{L} L_{x}-t_{z} L_{x} z_{x}-t_{e} L_{x} g\left(z_{x}\right)+\left(L-L_{x}\right) f_{y}\left(z_{y}\right) \\
L_{x} \in[0, L], \quad z_{x} \in\left[0, \mathrm{Z} / L_{x}\right]
\end{gathered}
$$

Because the maximand is strictly concave, the unique solution must satisfy the first-order conditions:

$$
\begin{aligned}
& \left(p+s_{x}\right) f_{x}\left(z_{x}\right)+s_{L}-t_{z} z_{x}-t_{e} g\left(z_{x}\right)-\left[f_{y}\left(z_{y}\right)+f_{y}^{\prime}\left(z_{y}\right)\left(z_{y}-z_{x}\right)\right]=0 \\
& \left(p+s_{x}\right) f_{x}^{\prime}\left(z_{x}\right)-t_{z}-t_{e} g^{\prime}\left(z_{x}\right)-f_{y}^{\prime}\left(z_{y}\right)=0
\end{aligned}
$$

Using the fact that $u_{x} / u_{y}=p$ and comparing (6) and (7) to (8) and (9), the welfare-maximizing policies $s_{x}, s_{L}, t_{z}$, and $t_{e}$ must satisfy:

$$
\begin{aligned}
& s_{x} f_{x}\left(z_{x}^{o}\right)+s_{L}-t_{z} z_{x}^{o}-t_{e} g\left(z_{x}^{o}\right)=\frac{u_{a}}{u_{y}}+\frac{u_{e}}{u_{y}} g\left(z_{x}^{o}\right) \\
& s_{x} f_{x}^{\prime}\left(z_{x}^{o}\right)-t_{z}+t_{e} g^{\prime}\left(z_{x}^{o}\right)=-\frac{u_{e}}{u_{y}} g^{\prime}\left(z_{x}^{o}\right)
\end{aligned}
$$

where the derivatives of $u(\cdot)$ are evaluated at the socially optimal levels $L_{x}{ }^{\mathrm{o}}$ and $z_{x}{ }^{\mathrm{o}}$. If pollution can be observed and measured, the simplest choice of policies is to set $\left(s_{x}, s_{L}, t_{z}, t_{e}\right)=\left(0, u_{a} / u_{y}, 0\right.$, $\left.-u_{e} / u_{y}\right)$. This policy scheme is the Pigouvian outcome where each externality is rewarded by its marginal social value. Thus, if the effluent can be taxed directly, neither an output subsidy nor an input tax is necessary.

A major difficulty in regulating agricultural pollution is that damages cannot be observed and policies must instead regulate outputs and inputs directly. ${ }^{6}$ If the effluent tax $t_{e}$ is eliminated,

\footnotetext{
${ }^{6}$ In principle, pollution could be inferred from observations on inputs if the pollution function is known or estimable. In this case, farmers would be charged from predicted levels of pollution based on their input use. Administratively, such a scheme would be inferior to one with an equivalent outcome that acts on inputs directly.
} 
equations (10) and (11) comprise a system of two equations in the three unknowns $s_{x}, s_{L}$, and $t_{z}$. This arrangement allows a degree of freedom in selecting policies, and suggests that a social optimum can be obtained by combining commodity policy with input taxes and subsidies. However, this result depends on the simplification of only two factors, and does not hold in general. Indeed, the possibility of using any commodity policy disappears if there exist other factors of production that are unregulated and do not affect the externalities $a$ and $e .^{7}$

Among the four policies in $s$, only $s_{L}$ and $t_{z}$ are both feasible (because they act on observable transactions) and remain valid in more general cases (because they do not act on other factors of production). If the policy set is limited to these two instruments, equations (10) and (11) imply they must satisfy:

$$
\begin{aligned}
& t_{z}=-\frac{u_{e}}{u_{y}} g^{\prime}\left(z_{x}^{o}\right) \\
& s_{L}=\frac{u_{a}}{u_{y}}+t_{z} z_{x}^{o}+\frac{u_{e}}{u_{y}} g\left(z_{x}^{o}\right)
\end{aligned}
$$

In words, the optimal tax is the marginal social cost of applying agricultural inputs at $z_{x}^{0}$. The optimal subsidy in equation (13) is made up of two components. First, farmers are rewarded for the amenity benefit per acre of farmland $u_{d} / u_{y}$. Substituting the expression for the tax into (13), the second and third terms of the subsidy are equal to $\left(u_{e} / u_{y}\right)\left[g\left(z_{x}^{o}\right)-g^{\prime}\left(z_{x}^{o}\right) z_{x}^{o}\right]=\left(u_{e} / u_{y}\right)\left(\partial e / \partial L_{x}\right)$ (see footnote 2). Thus, the subsidy rewards farmers by the combined social value of amenity benefits and the marginal change in pollution. This is a generalization of Holtermann's result for a single externality; a welfare maximum can be achieved through taxes/subsidies on inputs that penalize or reward each input by its marginal contribution to the externality. Here, the social

\footnotetext{
${ }^{7}$ To see this, suppose there were a third factor, $W$, that is neither taxed nor subsidized and does not influence $a$ or $e$. The socially optimal allocation of $W$ must satisfy $\left(u_{x} / u_{y}\right)\left(\partial F_{x} / \partial W\right)-\partial F_{y} / \partial W=0$, while the free market allocation can
} 
value of pollution $u_{e} / u_{y}$ and the change in pollution with respect to $L_{x}$ are both negative, and the optimal subsidy therefore exceeds the amenity value of farmland.

Therefore, even if agricultural land provides no landscape amenities (i.e., $u_{a} \equiv 0$ ), it should still be subsidized in conjunction with the input tax $t_{z}$. Further, subsidizing land by the "net" value of amenities per acre will not achieve an efficient allocation of resources. Landscape amenity value net of pollution cost is $\left[u_{a} / u_{y}+\left(u_{e} / u_{y}\right) g\left(z_{x}^{o}\right)\right]$, but a subsidy of this amount falls short of the optimal subsidy in (13) by the amount $t_{z} z_{x}^{o}$. Thus, an empirical study of the willingness-to-pay for farmland amenities will not estimate the appropriate land subsidy, even if it accounts for the cost of agricultural pollution. Determining whether this difference is likely to be empirically significant is an important goal of the empirical analysis below.

The optimal levels of $s_{L}$ and $t_{z}$ are based on the welfare maximizing allocations $L_{x}^{o}$ and $z_{x}^{o}$, which are in turn determined in a simultaneous system (equations (6) and (7)). Consequently, any change in the value of either externality (i.e., a shift in $u_{a} / u_{y}$ or $u_{e} / u_{y}$ ) would induce an adjustment in both the optimal allocation $\left(L_{x}^{o}, z_{x}^{o}\right)$ and policy choice $\left(s_{L}, t_{z}\right)$. For example, suppose the value of agricultural land amenities increases by $\$ b$ per acre. In general, this change would lead to some (non-zero) adjustment in the optimal input tax even if $u_{e} / u_{y}$ remains fixed, while the optimal land subsidy would change by some amount other than $\$ b$.

\section{Open Economies}

Suppose the economy described above is opened to international trade. For simplicity, assume that: (a) foreign and domestic production technologies are identical, (b) foreign agriculture does not generate any externalities, and (c) foreign utility does not depend on 
domestic allocations. Under these assumptions, the allocations that maximize global welfare are the solution to the following combined Pareto problem:

$$
\begin{array}{ll}
\max u\left(x, y, L_{x}, L_{x} g\left(z_{x}\right)\right)+\alpha u^{*}\left(x^{*}, y^{*}\right) \\
\text { subject to: } \quad x+x^{*}=L_{x} f_{x}\left(z_{x}\right)+L_{x}^{*} f_{x}\left(z_{x}^{*}\right) \\
y+y^{*}=\left(L-L_{x}\right) f_{y}\left(z_{y}\right)+\left(L^{*}-L_{x}^{*}\right) f_{y}\left(z_{y}^{*}\right) \\
\\
L_{x} \in[0, L], \quad z_{x} \in\left[0, Z / L_{x}\right], \\
L_{x}^{*} \in\left[0, L^{*}\right], \quad z_{x}^{*} \in\left[0, Z^{*} / L_{x}^{*}\right]
\end{array}
$$

where $\alpha$ is the relative welfare weight of foreign consumers, and asterisks denote foreign variables. The first-order necessary conditions for allocations of land and other inputs (assuming an interior solution) simplify to:

$$
u_{x} f_{x}\left(z_{x}\right)-u_{y}\left[f_{y}\left(z_{y}\right)-f_{y}^{\prime}\left(z_{y}\right)\left(z_{y}-z_{x}\right)\right]+u_{a}+u_{e} g\left(z_{x}\right)=0
$$

(14b) $u_{x} f_{x}^{\prime}\left(z_{x}\right)-u_{y} f_{y}^{\prime}\left(z_{y}\right)+u_{e} g^{\prime}\left(z_{x}\right)=0$

$$
u_{x}^{*} f_{x}\left(z_{x}^{*}\right)-u_{y}^{*}\left[f_{y}\left(z_{y}^{*}\right)-f_{y}^{\prime}\left(z_{y}^{*}\right)\left(z_{y}^{*}-z_{x}^{*}\right)\right]=0
$$

(14d) $u_{x}^{*} f_{x}^{\prime}\left(z_{x}^{*}\right)-u_{y}^{*} f_{y}^{\prime}\left(z_{y}^{*}\right)=0$

Equations (14a) and (14b) describe the optimal levels of $L_{x}$ and $z_{x}$, respectively, while (14c) and (14d) correspond to the optimal allocations in the foreign economy. In the foreign country, each factor is employed in agriculture until the marginal benefits of agricultural production equal the opportunity value of manufactured production. The domestic allocation equations include terms for the externalities, and are equivalent to the closed economy conditions in equations (6) and (7).

Though a global perspective is of theoretical interest, it is reasonable to assume that the home government wishes only to maximize domestic welfare. The remainder of this section determines the allocations that are optimal from this domestic viewpoint, and compares each 
outcome with those that maximize global welfare. The small country and large country cases are analyzed in turn.

A small open economy views the world price of agricultural goods as an exogenous variable. Now regarding $p$ as a parameter, national income is:

$$
I\left(L_{x}, z_{x}\right)=p L_{x} f_{x}\left(z_{x}\right)+\left(L-L_{x}\right) f_{y}\left(z_{y}\right)
$$

The social welfare maximization problem becomes:

$$
\begin{aligned}
\max & v\left(p, I\left(L_{x}, z_{x}\right), L_{x}, L_{x} g\left(z_{x}\right)\right) \\
& L_{x} \in[0, L], \quad z_{x} \in\left[0, Z / L_{x}\right]
\end{aligned}
$$

with first-order conditions:

$$
v_{I} I_{L}+v_{a}+v_{e} g\left(z_{x}\right)=0 \text { and } \quad v_{I} I_{z}+v_{e} L_{x} g^{\prime}\left(z_{x}\right)=0
$$

Substituting the derivatives of $I$ from the definition above and the envelope conditions $v_{I}=u_{y}, v_{a}$ $=u_{a}$, and $v_{e}=u_{e}$, these conditions reduce to (see appendix):

$$
\begin{aligned}
& p f_{x}\left(z_{x}\right)-\left[f_{y}\left(z_{y}\right)-f_{y}^{\prime}\left(z_{y}\right)\left(z_{y}-z_{x}\right)\right]+\frac{u_{a}}{u_{y}}+\frac{u_{e}}{u_{y}} g\left(z_{x}\right)=0 \\
& p f_{x}^{\prime}\left(z_{x}\right)-f_{y}^{\prime}\left(z_{y}\right)+\frac{u_{e}}{u_{y}} g^{\prime}\left(z_{x}\right)=0
\end{aligned}
$$

Because $p=u_{x} / u_{y}$, these conditions imply exactly the same factor allocation that maximizes world welfare in conditions (14a) and (14b). Therefore, the optimal domestic policy for a small open economy is also optimal from a global point of view.

If the home economy is large enough so that changes in domestic production and consumption affect the world price, the price must be regarded as endogenous. The policy problem becomes:

$$
\begin{array}{cl}
\max & v\left(\tilde{p}\left(L_{x}, z_{x}\right), \tilde{I}\left(L_{x}, z_{x}\right), L_{x}, L_{x} g\left(z_{x}\right)\right) \\
& L_{x} \in[0, L], \quad z_{x} \in\left[0, Z / L_{x}\right]
\end{array}
$$


The price and income relations $\tilde{p}$ and $\tilde{I}$ satisfy:

$$
\begin{aligned}
& x(\tilde{p}, \tilde{I}, \cdot)+x^{*}(\tilde{p})=L_{x} f_{x}\left(z_{x}\right) \\
& \tilde{I}=\tilde{p} L_{x} f_{x}\left(z_{x}\right)+\left(L-L_{x}\right) f_{y}\left(z_{y}\right)
\end{aligned}
$$

where the arguments of $\tilde{p}$ and $\tilde{I}$ have been suppressed to simplify notation, and $x^{*}(\cdot)$ is the demand for exports. The first-order conditions are:

$$
v_{p} \tilde{p}_{L}+v_{I} \tilde{I}_{L}+v_{a}+v_{e} g\left(z_{x}\right)=0 \quad \text { and } \quad v_{p} \tilde{p}_{z}+v_{I} \tilde{I}_{z}+v_{e} L_{x} g^{\prime}\left(z_{x}\right)=0
$$

Substituting the derivatives of $v\left(v_{I}=u_{y}, v_{a}=u_{a}, v_{e}=u_{e}\right)$ and $\tilde{I}$, the condition $\tilde{p}=u_{x} / u_{y}$, Roy's Identity $v_{p}=-x v_{I}$, and market clearing, these conditions become (demonstration in appendix):

$$
\begin{aligned}
& \frac{u_{x}}{u_{y}} f_{x}\left(z_{x}\right)+x^{*}(\tilde{p}) \tilde{p}_{L}-\left[f_{y}\left(z_{y}\right)-f_{y}^{\prime}\left(z_{y}\right)\left(z_{y}-z_{x}\right)\right]+\frac{u_{a}}{u_{y}}+\frac{u_{e}}{u_{y}} g\left(z_{x}\right)=0 \\
& \frac{u_{x}}{u_{y}} f_{x}^{\prime}\left(z_{x}\right)+x^{*}(\tilde{p}) \tilde{p}_{z}-f_{y}^{\prime}\left(z_{y}\right)+\frac{u_{e}}{u_{y}} g^{\prime}\left(z_{x}\right)=0
\end{aligned}
$$

Compared to those that maximize world welfare (equations (14a) and (14b)), each of these conditions contains the extra term $x^{*}(\cdot) \tilde{p}_{j}$, or the product of exports and the change in price with respect to factor $j$. Assuming that $x_{p}<0$ and $x_{p}^{*}<0$, the derivatives of the market clearing condition (15) with respect to $L_{x}$ and $z_{x}$ imply that $\tilde{p}_{L}<0$ and $\tilde{p}_{z}<0$. Thus, a domestic planner could decrease the world price by increasing either of the factor allocations to agriculture. If the domestic economy is an agricultural importer, then $x^{*}<0$ and the extra terms in each condition

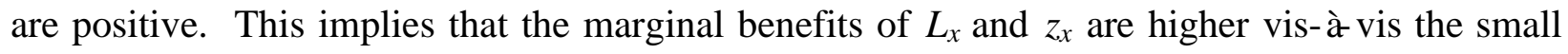
economy case, and the optimal allocations are therefore higher as well. If the home economy is an exporter $\left(x^{*}>0\right)$, the extra terms are negative, implying a smaller allocation of factors to agriculture. 
These results are intuitively consistent with the use of subsidies and taxes to regulate a single externality (Krutilla); importers gain from policies that increase production and decrease the world price, while the reverse is true for exporters. If policy interventions must be justified on the basis of external benefits and costs, the model predicts that importers' policies will emphasize the benefits of agricultural land and undervalue the environmental costs of agricultural inputs, while exporters are likely to do the opposite.

These predictions generally coincide with observed differences in policies and negotiating tactics across nations. Importers, such as Japan, Norway, and Switzerland, all have significant policy schemes aimed at protecting farmland, and argue for the importance of the extra-market benefits from agriculture in trade negotiations. If these countries retain domestic farmland against free market pressures, and succeed in convincing their trading partners to do the same, the resulting high level of agricultural production will lower world prices and benefit consumers in importing nations. Large exporters like the United States, on the other hand, have sought to protect the environment from agricultural pollution by "harmonizing up" environmental regulations across all trading partners. If this strategy is successful, world supply will contract due to the extra cost of environmental regulations, and producers in exporting countries will receive a higher price.

\section{A Stylized Empirical Application to U.S. Agriculture}

To illustrate the relationships between policies and their quantitative significance, this section simulates the model developed above for agricultural environmental policies in the United States. In the international trade arena, the United States is a net agricultural exporter, and has a significant market share of several major commodities. Thus, it is generally believed the U.S. is a "large" country because its trade volume is significant enough to have a measurable 
effect on world prices. Conversely, agriculture comprises only a small part of the U.S. economy. In 1994, the aggregate value added from agricultural production was $\$ 104$ billion or $1.5 \%$ of the \$6.9 trillion economy, and the cost of food items (which includes processing costs and the value of food retail services) make up only about $10 \%$ of household expenditure.

U.S. agriculture has been cited as the source of numerous forms of pollution such as soil erosion, nutrient runoff into streams and lakes, offensive odors, and contamination of water supplies. Here, the focus is on the harmful effects of agricultural chemicals on human health. This form of pollution was selected because its link to agriculture is well documented, the problem is widespread, and to date a limited (though growing) set of regulations have been imposed to control chemical use at the farm level. On the positive side, the agricultural landscape has been found to provide a significant amenity value to residents on the suburban fringes of major cities (Halstead, Krieger, Beasley et al.) These values have led to a significant policy interest in the preservation of open space, even at the national level of government (e.g., Office of Management and Budget).

\section{Simulation Model}

Based on the observations made above, several simplifying assumptions can be made in modeling the U.S agricultural sector. First, the small share of agriculture in gross domestic product implies that changes in the farm sector have almost no effect on prices or production in the rest of the economy. Second, the income effect on the demand for food items is likely to be negligible because it is a necessity item that makes up a small share of consumption expenditures. Third, although pollution and landscape amenities enter the utility function and therefore influence food demand, the ir effects are not thought to be empirically important. 
Given these simplifications, the agricultural sector can be described by the following model:

(20) $\quad x^{*}=B_{x}^{*} p^{-\eta_{x}^{*}}$

(21) $x+x^{*}=F_{x}\left(L_{x}, Z_{x}\right)$

$$
p \frac{\partial F_{x}}{\partial L_{x}}=p_{L}-s_{L}
$$

$$
p \frac{\partial F_{x}}{\partial Z_{x}}=p_{Z}+t_{Z}
$$

(26) $a=L_{x}$

(27) $e=L_{x} g\left(Z_{x} / L_{x}\right)$

where $\eta_{x}$ and $\eta_{x}{ }^{*}$ are the elasticities of domestic and export demand, respectively; $\eta_{L}$ and $\eta_{z}$ are the supply elasticities of the land and non-land inputs facing agriculture; $p_{L}$ and $p_{Z}$ are the equilibrium prices of land and non-land inputs; and the $B_{i}$ 's are demand and supply constants. This system of nine equations uniquely determines the nine unknowns: $x, x^{*}, L_{x}, Z_{x}, p, p_{L}, p_{Z}, a$, and $e$, which must be solved simultaneously with the land subsidy $s_{L}$ and input tax $t_{z}$.

Equations (19) and (20) specify the domestic and export demands to be of the constant elasticity form. Equation (21) is the market clearing condition for agricultural goods. The profit-maximizing conditions for land and non-land inputs are represented in (22) and (23), which state that the marginal value product of each factor must equal its (post-policy) market price. Equations (24) and (25) are the market clearing cond itions for land and non-land inputs, 
respectively, where the supplies of both factors are assumed to follow constant elasticity functions. Equations (26) and (27) are restatements from the conceptual model, relating the externalities $a$ and $e$ to the production factors $L_{x}$ and $Z_{x}$.

This model is based on a framework that has been widely used to simulate the aggregate effects of several different policies in agriculture (Floyd, Gardner). Though it describes the agricultural sector in isolation, the model preserves the relevant general equilibrium effects of non-fixed factor prices through the supply functions for $L_{x}$ and $Z_{x}$. In order to implement the model empirically, it is necessary to specify several functional relationships and parameter values. First, an aggregate utility function must be specified to calculate the welfare maximizing levels of $s_{L}$ and $t_{z}$. In addition, functional forms for $F_{x}$ and $g$ must be selected and parameterized, and parameter values for the supply and demand equations must also be chosen. These elements of the empirical model are discussed in turn below.

Aggregate utility is assumed to follow the money metric, quasilinear form (Mas-Collel et al.):

$$
u(x, y, a, e)=\phi(x)+y+\gamma a-\delta e
$$

where $\phi(\cdot)$ is the utility of food, $y$ is the dollar value of non-food consumption, $\gamma$ is the marginal value of landscape amenities, and $\delta$ is the marginal health cost of chemical pollution. $\phi(\cdot)$ represents the function that produces constant elasticity demands. Thus, maximizing (28) subject to the budget constraint $p x+y \leq I$ results in the demand function (19), which is independent of income and the environmental measures $a$ and $e$. To parameterize utility, values must be selected for the elasticity of demand $\eta_{x}$ (which appears in $\phi$ ), and the environmental parameters $\gamma$ and $\delta$. Based on a substantial body of empirical evidence that supports a highly inelastic demand for food, the parameter $\eta_{x}$ is varied over the range 0.2 to 0.5 . 
Poe (1999) summarizes several non-market valuation studies that have attempted to estimate the external benefits of farmland. Halstead, Bergstrom et al., and Krieger have converted estimates of household willingness to pay to amenity values per acre by aggregating over households to obtain social willingness to pay, and dividing by the number of acres in the study region. Applying the estimates from these studies to a similar conversion procedure for aggregate data, estimated amenity values of farmland range from less than $\$ 1$ per acre to $\$ 11$ per acre. Since the base values are from study regions where farmland is considered scarce, these per-acre values may be overestimated. The parameter $\gamma$ is thus varied from $\$ 0$ to $\$ 10$.

Because there is no standardized measure of agricultural pollution, $\delta$ is normalized to unity and $e$ is measured in dollars of health costs that are attributable to agricultural chemicals. The two primary categories of chemicals that pose health risks to humans are pesticides and nitrates that occur in drinking water from the use of nitrogen fertilizer. Because the health costs of these pollutants cannot be directly observed, we must rely on estimates from the environmental literature.

Poe (1998) has estimated a damage function that relates household willingness to pay for improved water quality to observed contamination levels. Households whose water supply exceeds the European health standard of $4.4 \mathrm{ppm}$ are willing to pay about $\$ 170$ per year for safer drinking water, while households that exceed the EPA standard of 10ppm are willing to pay an average of $\$ 380$. Based on population data compiled by the Environmental Working Group, these estimates imply aggregate nitrate damages of approximately $\$ 2.3$ billion. Other studies have estimated household willingness-to-pay for general improvements in water quality, including the removal of all agricultural and industrial contaminants (Schultz; Lindsay; Powell). 
These estimates imply aggregate damages from all water pollutants in the range of $\$ 3.8$ to $\$ 6.2$ billion per year.

Pimentel et al. estimate that the direct health cost of pesticides (including treatment of poisonings and pesticide-induced cancers as well as accidental fatalities) total $\$ 780$ million per year, and that the indirect costs through drinking water contamination are $\$ 1.8$ billion per year. Combining the direct and indirect health costs of all agricultural chemicals, the body of evidence suggests aggregate damages in the range of $\$ 3$ to $\$ 7$ billion, although these may be overestimates because they potentially account for non-agricultural contaminants. The base value of $e$ is thus varied from $\$ 2$ billion to $\$ 5$ billion.

The functional relationship between chemical application rates and damage to human health is not yet completely understood. Because yield is a concave function of polluting inputs, physical properties imply the pollution function must be convex (Siebert et al.). Thus, convexity is a natural property to impose on the health costs of pollutants as well, but there is little scientific justification for any particular functional form. Here, health costs are assumed to follow a quadratic form: $e=B_{e} Z_{x}^{2} / L_{x}=L_{x} B_{e} z_{x}^{2}$. This function has linear derivatives in $Z_{x}$ and $z_{x}$, and therefore imposes constant marginal health costs. Thus, the specification is a linear approximation to the underlying marginal health cost function; this simplification seemed reasonable given the stylized focus of the application and the approximate nature of the data.

Data on aggregate agricultural production is available from the USDA-Economic Research Service (Ahearn et al., Ball et al.). This data series includes indices of aggregate output as well as inputs in several categories for the years 1948-1994. For purposes here, agricultural technology was assumed to be separable so that input categories can be further grouped into a "land aggregate" $\left(\mathbb{L}_{x}\right)$, which is made up of land and other factors that are 
combined with it, and a "non-land aggregate" $Z_{x}$. In particular, the land aggregate includes indexes of land itself, capital equipment, and labor; the non-land aggregate is made up of chemicals, fuel and electricity, and other purchased inputs. When technology is separable, the production decision can be divided into two stages, where inputs are combined in a least-cost way within each aggregate in the first stage, and the profit maximizing levels of the aggregates are chosen in the second stage (Chambers).

To be able to compute quantity and price series for $L_{x}$ and $Z_{x}$, it is necessary to employ an indexing procedure that combines the inputs within each aggregate factor. Because the underlying functional form of the technology is unknown, any index must be regarded as an approximation that reflects the productive capacity of the various inputs. Here, it is assumed that the inputs within each aggregate are combined in Leontief fixed proportions. Though this procedure abstracts from substitution of the inputs within the aggregates, it greatly simplifies the analysis because the implicit price of each aggregate becomes a linear expression of the category prices. Consequently, a subsidy on land alone is equivalent to a subsidy on the entire land aggregate $L_{x}$, and a tax on chemicals is equivalent to a tax on the non-land aggregate $Z_{x}{ }^{8}$

To solve the second stage problem, it is necessary to specify a functional form that relates $L_{x}$ and $Z_{x}$ to agricultural output. Here, a Cobb-Douglas form is assumed: $F_{x}\left(L_{x}, Z_{x}\right)=B_{x} L_{x}^{\beta_{L}} Z_{x}^{\beta_{Z}}$,

\footnotetext{
${ }^{8}$ In particular, the aggregate factor index functions are:

$$
L_{x}(l, K, N)=\min \left\{l, K / b_{K}, N / b_{N}\right\} \quad \text { and } \quad Z_{x}(C, E, M)=\min \left\{C, E / b_{E}, M / b_{M}\right\}
$$

where $l$ represents land, $K$ is capital, $N$ is labor, $C$ is chemicals, $E$ is fuel and electricity, and $M$ is purchased materials. The coefficients $b_{K}$ and $b_{N}$ are the quantities of capital and labor that must be combined with each acre of land, respectively, and $b_{E}$ and $b_{M}$ are the amounts of energy and materials used with each unit of chemicals. The implicit price of the land aggregate is the cost function of $L_{x}$, or: $p_{L}=\min \left\{p_{l} l+p_{K} K+p_{N} N: L_{x}(l, K, N)=1\right\}=p_{l}+$ $b_{K} p_{K}+b_{N} p_{N}$. By a parallel argument, the price of the non-land aggregate is: $p_{Z}=p_{C}+b_{E} p_{E}=b_{M} p_{M}$. Thus, an addition or subtraction to $p_{l}$ or $p_{C}$ implies the same change in $p_{L}$ and $p_{Z}$. If there are substitution possibilities within the aggregate factors, the linear price relation is a first-order approximation to a concave function. Since this concave function rises more slowly for price increases and falls more quickly for price decreases, the linear approximation will estimate a lower bound on the subsidy and an upper bound on the tax.
} 
where $\beta_{L}+\beta_{Z}=1$ by constant returns to scale. Under profit maximization, $\beta_{L}$ and $\beta_{Z}$ are the cost shares of the land and non-land aggregates, respectively. Calculating the average shares over the years 1948-1994 resulted in point estimates of $\beta_{L}=0.71$ and $\beta_{Z}=0.29$; the parameters are varied over the ranges $[0.5,0.9]$ for $\beta_{L}$ and $[0.1,0.5]$ for $\beta_{Z}$.

The remaining parameters to be chosen are the elasticity of export demand and the supply elasticities for the aggregate factors $L_{x}$ and $Z_{x}$. Export demand is probably quite elastic, but may not be perfectly elastic because the U.S. is a large country. To explore the consequences of market power in international trade, the export demand elasticity was varied between 2 and $\infty$. The extreme values represent the polar cases of a very large economy with substantial market power, and a small economy with no market power. Because land makes up a significant part of the aggregate $L_{x}$, we would expect its supply elasticity to be quite small. On the other hand, the inputs in $Z_{x}$ can be produced at very nearly constant cost, implying a relatively high supply elasticity. Thus, the parameters $\eta_{L}$ and $\eta_{Z}$ are varied over the ranges $[0.1,0.3]$ and $[5,15]$, respectively. Table 1 summarizes the range of parameter values, along with a set of "primary" values that are used in the simulations reported below. The constants $B_{i}$ are determined by calibrating the model relationships to base data for 1994; these base values are reported in the second column of table 2 .

Results

To explore the relationships among domestic environmental policies, the model is initially solved under three policy experiments for the small economy case. The assumption of a small economy precludes the possibility of distorting trade, and ensures that the simulated policies include only externality-correcting components. In the first policy scenario, chemicals 
Table 1. Parameter Values

\begin{tabular}{lccc}
\hline Parameter & Symbol & Range & Primary Value \\
\hline Elasticity of domestic demand & $\eta_{x}$ & $0.2-0.5$ & 0.3 \\
Elasticity of export demand & $\eta_{x}^{*}$ & $2-\infty$ & 5 \\
Supply elasticity of $L_{x}$ & $\eta_{L}$ & $0.1-0.3$ & 0.2 \\
Supply elasticity of $Z_{x}$ & $\eta_{Z}$ & $5-15$ & 10 \\
Production elasticity of $L_{x}$ & $\beta_{L}$ & $0.5-0.9$ & 0.71 \\
$\begin{array}{l}\text { Production elasticity of } Z_{x} \\
\text { Marginal value of amenities }(\$ / a)\end{array}$ & $\beta_{Z}$ & $0.1-0.5$ & 0.29 \\
$\begin{array}{l}\text { Aggregate external health costs } \\
\text { (\$billion) }\end{array}$ & $\gamma$ & $0-10$ & 5 \\
\hline
\end{tabular}

are taxed at their marginal external cost with no land policy, while the second scenario subsidizes land at its amenity value but does not tax non-land inputs. These two experiments thus correspond to policy schemes that target each externality independently. The third experiment is based on the relationships derived in the theoretical section and includes both a land subsidy and a chemical tax that simultaneously correct both externalities.

The results of these experiments are reported in table 2. When the tax is imposed in isolation (scenario 1), farmers pay a $\$ 0.13$ tax per pound of chemicals. ${ }^{9}$ Even though estimated chemical use and health costs fall in this scenario (by about $14 \%$ and $27 \%$, respectively), the increased cost of farming drives land out of agriculture and reduces total production. Thus, in an independent effort to improve water quality, the tax policy has damaged the public-good function of agriculture and has reduced the aggregate value of farm production. If instead a subsidy is

\footnotetext{
${ }^{9}$ Note that chemicals include all nutrients and the active ingredients of pesticides.
} 
Table 2. Base Data and Simulation Results ${ }^{a}$

\begin{tabular}{|c|c|c|c|c|c|}
\hline \multirow[b]{2}{*}{ Variable } & \multirow[b]{2}{*}{$\begin{array}{c}\text { Base Data } \\
(1994) \\
\end{array}$} & \multicolumn{3}{|c|}{ Small Economy } & \multirow[b]{2}{*}{$\begin{array}{c}\text { Large } \\
\text { Economy }^{b}\end{array}$} \\
\hline & & $\begin{array}{c}\text { Tax Only } \\
\text { (Scenario 1) } \\
\end{array}$ & $\begin{array}{l}\text { Subs. Only } \\
\text { (Scenario 2) } \\
\end{array}$ & $\begin{array}{l}\text { Joint Policy } \\
\text { (Scenario 3) } \\
\end{array}$ & \\
\hline Land Subsidy (\$/acre) & 0.00 & 0.00 & 5.00 & 7.67 & -7.38 \\
\hline Chemical Tax (\$/lb.) & 0.00 & 0.13 & 0.00 & 0.13 & 0.29 \\
\hline Food Price $^{c}$ & 1.00 & 1.00 & 1.00 & 1.00 & $\begin{array}{c}1.09 \\
8.7\end{array}$ \\
\hline Production ( $\$$ billion) & 166.61 & $\begin{array}{c}158.32 \\
-5.0\end{array}$ & $\begin{array}{c}167.91 \\
0.8\end{array}$ & $\begin{array}{c}160.29 \\
-3.8\end{array}$ & $\begin{array}{c}170.04 \\
2.1\end{array}$ \\
\hline Net Exports ( $\$$ billion) & 19.17 & $\begin{array}{r}10.88 \\
-43.2\end{array}$ & $\begin{array}{c}20.46 \\
6.7\end{array}$ & $\begin{array}{l}12.85 \\
-33.0\end{array}$ & $\begin{array}{l}13.73 \\
-28.4\end{array}$ \\
\hline Consumption ( $\$$ billion) & 147.44 & 147.44 & 147.44 & 147.44 & $\begin{array}{c}156.31 \\
6.0\end{array}$ \\
\hline $\begin{array}{l}\text { Agricultural Land } \\
\text { (million acres) }\end{array}$ & 975 & $\begin{array}{l}967 \\
-0.8\end{array}$ & $\begin{array}{r}983 \\
0.8\end{array}$ & $\begin{array}{l}979 \\
0.4\end{array}$ & $\begin{array}{l}968 \\
-0.7\end{array}$ \\
\hline Rent on Land (\$/acre) & 121.35 & $\begin{array}{c}116.30 \\
-4.2\end{array}$ & $\begin{array}{c}126.32 \\
4.1\end{array}$ & $\begin{array}{c}123.93 \\
2.1\end{array}$ & $\begin{array}{c}117.31 \\
-3.3\end{array}$ \\
\hline $\begin{array}{l}\text { Chemical Use } \\
\text { (billion lb.) }\end{array}$ & 44.8 & $\begin{array}{c}38.3 \\
-14.4\end{array}$ & $\begin{array}{c}45.1 \\
0.7\end{array}$ & $\begin{array}{c}38.8 \\
-13.4\end{array}$ & $\begin{array}{c}36.6 \\
-18.2\end{array}$ \\
\hline $\begin{array}{l}\text { Price of Chemicals } \\
(\$ / 1 b .)\end{array}$ & 1.08 & $\begin{array}{l}1.06 \\
-1.5\end{array}$ & $\begin{array}{c}1.08 \\
0.1\end{array}$ & $\begin{array}{l}1.06 \\
-1.4\end{array}$ & $\begin{array}{l}1.06 \\
-2.0\end{array}$ \\
\hline $\begin{array}{l}\text { Input Intensity } \\
\text { (lb./acre) }\end{array}$ & 46.0 & $\begin{array}{c}39.7 \\
-13.6\end{array}$ & $\begin{array}{l}45.9 \\
-0.1\end{array}$ & $\begin{array}{c}39.6 \\
-13.7\end{array}$ & $\begin{array}{c}37.8 \\
-17.6\end{array}$ \\
\hline Health Costs ( $\$$ billion) & 3.50 & $\begin{array}{l}2.56 \\
-27.0\end{array}$ & $\begin{array}{c}3.52 \\
0.6\end{array}$ & $\begin{array}{c}2.61 \\
-25.3\end{array}$ & $\begin{array}{c}2.36 \\
-33.4\end{array}$ \\
\hline $\begin{array}{l}\text { Land Amenity Value } \\
(\$ \text { billion })^{d}\end{array}$ & 4.87 & $\begin{array}{r}4.83 \\
-0.8 \\
\end{array}$ & $\begin{array}{c}4.91 \\
0.8 \\
\end{array}$ & $\begin{array}{c}4.89 \\
0.4 \\
\end{array}$ & $\begin{array}{l}4.84 \\
-0.7 \\
\end{array}$ \\
\hline
\end{tabular}


introduced to protect farmland without any regulations on chemical use (scenario 2), the stock of farmland and the value of production increase from their base values, but so do aggregate chemical use and estimated health costs. In sum, a policy to independently improve one externality leads to an adverse change in the other.

Only if the subsidy and tax are imposed jointly can there be an improvement in both externalities (scenario 3). The tax on chemicals of $\$ 0.13$ per lb., if imposed jointly with the land subsidy of $\$ 7.67$ per acre, will achieve an efficient allocation of both factors. Farmland rises from its base value by 4 million acres, and external health costs fall by an estimated $\$ 900$ million (25\%). The optimal subsidy on an acre of farmland includes the $\$ 5$ it contributes to amenity value as well as its marginal effect on pollution; an extra acre of agricultural land, ceteris paribus, reduces external health costs by $\$ 2.67$. Thus, the optimal subsidy differs from the amenity value of farmland by more than $50 \%$.

In the joint policy case, the fall in non-land inputs outweighs the effect of the increase in farmland, and domestic production decreases by $\$ 6.6$ billion. Net exports contract by a matching amount, but the international price is not affected because of the small economy assumption. If the economy is large enough so that export quantities influence the world price, optimal environmental policies include components that improve domestic welfare through trade distortion. Thus, the resulting tax and subsidy may differ substantially from the external cost of chemicals and amenity benefits of farmland.

The last column in table 2 corresponds to this large economy case, where the tax and subsidy are imposed jointly and the elasticity of export demand is set at 5. Since the U.S. is an exporter, it will have an incentive to select policies that restrict production and in turn, raise the international price. Therefore, the chemical tax of $\$ 0.29$ is more than twice as high as the small 
economy case, while the subsidy becomes negative $(-\$ 7.38)$ so that land is taxed as well. These policies do result in some environmental improvements because external health costs are reduced by over $30 \%$, but these gains are partially offset by a $0.7 \%$ decrease in the stock of farmland.

The "environmental" policies provide additional welfare benefits through trade distortion. They have succeeded in raising international prices by $9 \%$ and expanding U.S. production by 2\%. Net exports decrease compared to base values where environmental consequences are ignored completely, but are about $\$ 900$ million larger than the small economy case where tradedistorting effects are precluded.

Though the cases of alternative parameter values are not reported, the results in table 2 are generally quite robust as market and production parameters are varied. With environmental parameters set at their primary values and the other domestic parameters $\left(\eta_{x}, \eta_{L}, \eta_{Z}, \beta_{L}\right.$, and $\left.\beta_{Z}\right)$ individually varied across their ranges, the small economy tax ranges from $\$ 0.12$ to $\$ 0.14$ per lb. while the subsidy is between $\$ 7.04$ and $\$ 7.81$ per acre. These parameters have a somewhat greater impact on the policies for a large economy; with the export elasticity set at 5 , the tax and subsidy range from $\$ 0.18$ to $\$ 0.39$ per 1 b. and from $-\$ 12.79$ to $-\$ 2.40$ per acre, respectively. The environmental and trade parameters naturally have a more direct effect on the environmental policies. The different environmental values would imply small economy input taxes from $\$ 0.08$ to $\$ 0.18$ per $\mathrm{lb}$. and small economy land subsidies between $\$ 2.68$ and $\$ 12.67$ per acre. With environmental parameters at their primary values, the extreme case of an export demand elasticity of 2 implies an optimal tax and subsidy of $\$ 0.37$ per $1 b$. and $-\$ 14.28$ per acre, respectively. 


\section{Policy Implications}

This paper has determined the optimal policy rules when agricultural production generates both landscape amenities and pollution from chemical inputs. The optimal subsidy on land and tax on non-land inputs depend on the size of both externalities, and a change in the social value of either land amenities or pollution therefore implies a change in both policies. It has been shown empirically that independent policies are likely to work at cross-purposes; a single policy directed at one externality leads to an adverse change in the other externality.

One important implication for empirical research is that an optimal subsidy on agricultural land does not equal the net value of land amenities. Numerous studies have estimated the social amenity benefits from land in agriculture using non-market valuation techniques, but these estimates cannot be interpreted as the appropriate farmland subsidy, even if the values are "corrected" to account for the value of pollution generated per acre. A simulation of U.S. agriculture suggests the interaction between policies is empirically important; if the incentive to use environmental policy as a trade-distorting tool is ignored, the estimated optimal land subsidy is about $50 \%$ larger than the amenity value of farmland. In the large economy case, the policies include components that improve domestic welfare through terms of trade, and the optimal tax and subsidy differ even more from the social values of the two external effects.

The model here abstracts from the site-specific factors that cause environmental values to be spatially heterogeneous. As a practical matter, proposed policies differ by location, and tend to focus on areas that are known to be environmentally sensitive or farming regions in close proximity to large population centers. Yet our findings are even more important for policy making in these areas, because the interaction among joint policies is more pronounced if the social values placed on the external effects from agricultural production are large. 
In the international arena, small economies will choose the same policies that maximize world welfare, but large economies have an incentive to set policies at non-internalizing levels to exploit terms of trade effects. In particular, large importers will choose policies that increase agricultural factors beyond globally efficient allocations, while large exporters prefer to restrict factor allocations (and hence agricultural production) to raise the international price. For large economies, production policies that are ostensibly justified on environmental grounds can become instruments to distort international prices. Indeed, based on empirical policy simulations, we estimate the U.S. alone could manipulate its domestic environmental policies to change the world price by about $9 \%$.

Even for small countries with environmental concerns, there are additional policy goals such as supporting farm incomes or enhancing food security. In the WTO negotiations over environmental issues, therefore, it may impossible to determine whether so-called environmental policies are really vehicles to help achieve some other goal. The key to making domestic policies compatible with free trade lies in the types of policies used. The less the policy instruments distort trade, the more autonomy nations can have in selecting and executing domestic policy goals. 


\section{Appendix}

\section{Derivation of Optimal Factor Allocation Conditions: Closed Economy}

From equation (2) the derivatives of national income $I$ are:

$$
\begin{aligned}
& I_{L}=p_{L} L_{x} f_{x}\left(z_{x}\right)+p(\cdot) f_{x}\left(z_{x}\right)-\left[f_{y}\left(z_{y}\right)-f_{y}^{\prime}\left(z_{y}\right)\left(z_{y}-z_{x}\right)\right] \\
& I_{z}=p_{z} L_{x} f_{x}\left(z_{x}\right)+p(\cdot) L_{x} f_{x}^{\prime}\left(z_{x}\right)-L_{x} f_{y}^{\prime}\left(z_{y}\right)
\end{aligned}
$$

Substituting these derivatives and Roy's Identity $\left(v_{p}=-x(p, I) v_{I}\right)$ into equations (4) and (5):

$$
\begin{aligned}
& -x(p, I) v_{I} p_{L}+v_{I} p_{L} L_{x} f_{x}\left(z_{x}\right)+v_{I} p(\cdot) f_{x}\left(z_{x}\right)-v_{I}\left[f_{y}\left(z_{y}\right)-f_{y}^{\prime}\left(z_{y}\right)\left(z_{y}-z_{x}\right)\right]+v_{a}+v_{e} g\left(z_{x}\right)=0 \\
& -x(p, I) v_{I} p_{z}+v_{I} p_{z} L_{x} f_{x}\left(z_{x}\right)+v_{I} p(\cdot) L_{x} f_{x}^{\prime}\left(z_{x}\right)-v_{I} L_{x} f_{y}^{\prime}\left(z_{y}\right)+v_{e} L_{x} g^{\prime}\left(z_{x}\right)=0
\end{aligned}
$$

The market clearing condition (equation 1)) implies that the sum of the first and second terms in each of the above equations is zero. The Envelope Theorem implies that $v_{I}=u_{y}, v_{a}=u_{a}$, and $v_{e}=$ $u_{e}$; and $p(\cdot)=u_{x} / u_{y}$ by the first-order conditions of utility maximization. Substituting these relationships into the remaining non-zero terms and dividing the second equation by $L_{x}$ :

$$
\begin{aligned}
& u_{x} f_{x}\left(z_{x}\right)-u_{y}\left[f_{y}\left(z_{y}\right)-f_{y}^{\prime}\left(z_{y}\right)\left(z_{y}-z_{x}\right)\right]+u_{a}+u_{e} g\left(z_{x}\right)=0 \\
& u_{y} x^{\prime}\left(z_{x}\right)-u_{y} f_{y}^{\prime}\left(z_{y}\right)+u_{e} g^{\prime}\left(z_{x}\right)=0
\end{aligned}
$$

Dividing each of these equations by $u_{y}$ reveals equations (6) and (7) in the paper.

\section{Derivation of Optimal Factor Allocation Conditions: Small Open Economy}

Because the price $p$ is a parameter for small economies, the derivatives of national income $I$ are:

$$
\begin{aligned}
& I_{L}=p f_{x}\left(z_{x}\right)-\left[f_{y}\left(z_{y}\right)-f_{y}{ }^{\prime}\left(z_{y}\right)\left(z_{y}-z_{x}\right)\right] \\
& I_{z}=p L_{x} f_{x}{ }^{\prime}\left(z_{x}\right)-L_{x} f_{y}{ }^{\prime}\left(z_{y}\right)
\end{aligned}
$$

Substituting these derivatives and the envelope conditions $\left(v_{I}=u_{y}, v_{a}=u_{a}\right.$, and $\left.v_{e}=u_{e}\right)$ into the welfare maximizing conditions:

$$
u_{y} p f_{x}\left(z_{x}\right)-u_{y}\left[f_{y}\left(z_{y}\right)-f_{y}^{\prime}\left(z_{y}\right)\left(z_{y}-z_{x}\right)\right]+u_{a}+u_{e} g\left(z_{x}\right)=0
$$




$$
u_{y} p L_{x} f_{x}^{\prime}\left(z_{x}\right)-u_{y} L_{x} f_{y}^{\prime}\left(z_{y}\right)_{z}+u_{e} L_{x} g^{\prime}\left(z_{x}\right)=0
$$

The small economy conditions on page 13 are obtained by dividing the first of these equations by $u_{y}$ and the second by $u_{y} L_{x}$.

\section{Derivation of Optimal Factor Allocation Conditions: Large Open Economy}

From equation (16) the derivatives of the large-economy national income function $\tilde{I}$ are:

$$
\begin{aligned}
& \tilde{I}_{L}=\tilde{p}_{L} L_{x} f_{x}\left(z_{x}\right)+\tilde{p}(\cdot) f_{x}\left(z_{x}\right)-\left[f_{y}\left(z_{y}\right)-f_{y}^{\prime}\left(z_{y}\right)\left(z_{y}-z_{x}\right)\right] \\
& \tilde{I}_{z}=\tilde{p}_{z} L_{x} f_{x}\left(z_{x}\right)+\tilde{p}(\cdot) L_{x} f_{x}^{\prime}\left(z_{x}\right)-L_{x} f_{y}^{\prime}\left(z_{y}\right)
\end{aligned}
$$

Substituting these derivatives and Roy's Identity $\left(v_{p}=-x v_{I}\right)$ into the conditions for a welfare maximum:

$$
\begin{aligned}
& -x(\tilde{p}, \tilde{I}) v_{I} \tilde{p}_{L}+v_{I} \tilde{p}_{L} L_{x} f_{x}\left(z_{x}\right)+v_{I} \tilde{p}(\cdot) f_{x}\left(z_{x}\right)-v_{I}\left[f_{y}\left(z_{y}\right)-f_{y}^{\prime}\left(z_{y}\right)\left(z_{y}-z_{x}\right)\right]+v_{a}+v_{e} g\left(z_{x}\right)=0 \\
& -x(\tilde{p}, \tilde{I}) v_{I} \tilde{p}_{z}+v_{I} \tilde{p}_{z} L_{x} f_{x}\left(z_{x}\right)+v_{I} \tilde{p}(\cdot) L_{x} f_{x}^{\prime}\left(z_{x}\right)-v_{I} L_{x} f_{y}^{\prime}\left(z_{y}\right)+v_{e} L_{x} g^{\prime}\left(z_{x}\right)=0
\end{aligned}
$$

By the market clearing condition (equation (15)), the sum of the first and second terms in the first of the foregoing equations is $x^{*}(\tilde{p}) \tilde{p}_{L} v_{I}$. Similarly, the first and second terms in the second equation sum to $x^{*}(\tilde{p}) \tilde{p}_{z} v_{I}$. Proceeding as above, substitute these relationships along with the envelope and utility maximization conditions $\left(v_{I}=u_{y}, v_{a}=u_{a}\right.$, and $v_{e}=u_{e}$; and $\left.\tilde{p}=u_{x} / u_{y}\right)$ into the preceding conditions and divide the second condition by $L_{x}$ :

$$
\begin{aligned}
& x^{*}(\tilde{p}) \tilde{p}_{L} u_{y}+u_{x} f_{x}\left(z_{x}\right)-u_{y}\left[f_{y}\left(z_{y}\right)-f_{y}^{\prime}\left(z_{y}\right)\left(z_{y}-z_{x}\right)\right]+u_{a}+u_{e} g\left(z_{x}\right)=0 \\
& \frac{x^{*}(\tilde{p}) \tilde{p}_{z} u_{y}}{L_{x}}+u_{y} f_{x}^{\prime}\left(z_{x}\right)-u_{y} f_{y}^{\prime}\left(z_{y}\right)+u_{e} g^{\prime}\left(z_{x}\right)=0
\end{aligned}
$$

Dividing each of these equations by $u_{y}$ reveals equations (17) and (18). 
For exporters (importers), the term $x^{*}(\tilde{p}) \tilde{p}_{j}(j=L, z)$ in equations (17) and (18) will be negative (positive) as claimed in the text provided that the derivatives of $\tilde{p}(\cdot)$ are negative. To determine the signs of $\tilde{p}_{L}$ and $\tilde{p}_{z}$, differentiate the market clearing condition (15) to obtain:

(15b) $x_{p} \tilde{p}_{z}+x_{I} \tilde{I}_{z}+x_{p}^{*} \tilde{p}_{z}=L_{x} f_{x}^{\prime}\left(z_{z}\right)$

Solving condition (17) for $\left(u_{x} / u_{y}\right) f_{x}\left(z_{x}\right)=\tilde{p}(\cdot) f_{x}\left(z_{x}\right)$ and substituting the resulting expression into $\tilde{I}_{L}$ above:

$$
\tilde{I}_{L}=\tilde{p}_{L} L_{x} f_{x}\left(z_{x}\right)-x^{*}(\tilde{p}) \tilde{p}_{L}-\frac{u_{a}}{u_{y}}-\frac{u_{e}}{u_{y}} g\left(z_{x}\right)=x(\cdot) \tilde{p}_{L}-\frac{u_{a}}{u_{y}}-\frac{u_{e}}{u_{y}} g\left(z_{x}\right)
$$

where the second equality follows from market clearing. Similarly, equation (18) and the expression for $\tilde{I}_{z}$ above imply:

$$
\tilde{I}_{z}=x(\cdot) \tilde{p}_{z}-L_{x} \frac{u_{e}}{u_{y}} g^{\prime}\left(z_{x}\right)
$$

Substituting the foregoing expressions for $\tilde{I}_{L}$ and $\tilde{I}_{z}$ into equations (15a) and (15b) and rearranging:

$$
\begin{gathered}
\tilde{p}_{L}=\frac{f_{x}(\cdot)+x_{I} \frac{u_{a}}{u_{y}}+x_{I} \frac{u_{e}}{u_{y}} g\left(z_{z}\right)}{x_{p}+x_{I} x(\cdot)+x_{p}^{*}} \\
\tilde{p}_{z}=\frac{L_{x}\left[f_{x}^{\prime}(\cdot)+x_{I} \frac{u_{e}}{u_{y}} g^{\prime}\left(z_{z}\right)\right]}{x_{p}+x_{I} x(\cdot)+x_{p}^{*}}
\end{gathered}
$$

The Slutsky equation and the assumption that $x_{p}^{*}<0$ ensure that the denominator of both of these expressions is regative. Assuming that food is a normal good, the numerator of $\tilde{p}_{L}$ is 
always positive when $\left(u_{a} / u_{y}\right)+\left(u_{e} / u_{y}\right) g\left(z_{x}\right)>0$ (i.e., when net externalities are positive). A sufficient set of conditions for both numerators to be positive is:

$$
\begin{aligned}
& \tilde{p} f_{x}(\cdot)+\frac{u_{a}}{u_{y}}+\frac{u_{e}}{u_{y}} g\left(z_{x}\right)>0 \\
& \tilde{p} f_{x}^{\prime}(\cdot)+\frac{u_{e}}{u_{y}} g^{\prime}\left(z_{x}\right)>0
\end{aligned}
$$

Thus, as long as the net marginal benefit of each factor in agriculture is positive (i.e., the sum of marginal private and external benefits outweigh marginal costs), the price function must be decreasing in both arguments. Alternative cases (for example, when the cost of pollution on each acre is larger than the combined value of farm production and amenity benefits) are ruled out by assumption. 


\section{References}

Australian Bureau of Agricultural and Resource Economics (ABARE) “'Multifunctionality': A Pretext for Protection"? ABARE Current Issues 99.3 August 1999. http://www.abare.gov.au/pubcat/trade.htm

Ahearn, M., J. Yee, V.E. Ball, R. Nehring, A. Somwaru, and R. Evans. Agricultural Productivity in the United States. United States Department of Agriculture, Economic Research Service, Agriculture Information Bulletin No. 740, 1998.

Anderson, K. (1992a) "Agricultural Trade Liberalization and the Environment: A Global Perspective." The World Economy 15(1992):153-72.

Anderson, K. (1992b) "The Standard Welfare Economics of Policies Affecting Trade and the Environment." in The Greening of World Trade Issues, Anderson, K. and R. Black, eds. Ann Arbor: University of Michigan Press, 1992.

Anderson, K. and B. Hoekman. "Agriculture and the New Trade Agenda." Paper presented at the American Economic Association Annual Meeting, New York, January 3-5, 1999.

Ball, V.E., J. Bureau, R. Nehring, and A. Somwaru. "Agricultural Productivity Revisited." American Journal of Agricultural Economics 79(1997): 1045-63.

Beasley, S.D., W.C. Workman, and N.A. Williams. "Estimating Amenity Values on Urban Fringe Farmland: A Contingent Valuation Approach." Growth and Change 17(1986): 7078.

Beghin, J., S. Dessus, D. Roland-Holst and D. van der Mensbrugghe. "The Trade and Environment Nexus in Mexican Agriculture. A General Equilibrium Analysis" Agricultural Economics 17 (December 1997):115-32.

Bergstrom, J.C., B.L. Dillman, and J.R. Stoll. "Public Environmental Amenity Benefits of Private Land: The Case of Prime Agricultural Land." Southern Journal of Agricultural Economics 17(1985):139-49.

Blandford, D. and L. Fulponi. "Emerging Public Concerns in Agriculture: Domestic Policies and International Trade Commitments." European Review of Agricultural Economics 26(1999): 409-24.

Bohman, M., J. Cooper, D. Mullarkey, M.A. Normile, D. Skully, S. Vogel, and E. Young. "The Use and Abuse of Multifunctionality." Economic Research Service, USDA, November, 1999. http://www.econ.ag.gov/briefing/wto/

Chambers, R.G. Applied Production Analysis: A Dual Approach. New York: Cambridge University Press, 1988. 
Copeland, B.R. "International Trade and the Environment: Policy Reform in a Polluted Small Open Economy." Journal of Environmental Economics and Management 26(1994): 4465.

Dixit, A. and V. Norman. Theory of International Trade: A Dual, General Equilibrium Approach London: Cambridge University Press, 1980

Environmental Working Group. "Pouring it On: Nitrate Contamination of Drinking Water." Manuscript, Washington, DC, 1996.

Floyd, J.E. "The Effects of Farm Price Supports on the Return to Land and Labor in Agriculture." Journal of Political Economy 73(1965): 148-58.

Gardner, B.L. The Economics of Agricultural Policies. New York: Macmillan, 1987.

Halstead, J.M. "Measuring the Nonmarket Value of Massachusetts Agricultural Land: A Case Study." Journal of the Northeastern Agricultural Economics Council 13(1984): 12-19.

Hackl, F. and G.J. Pruckner. “Towards More Efficient Compensation Programmes for Tourists' Benefits from Agriculture in Europe." Environmental and Resource Economics 10(1997): 189-205.

Holtermann, S. "Alternative Tax Systems to Correct for Externalities and the Efficiency of Paying Compensation.” Economica 43(1976):1-16.

Krieger, D.J. "Saving Open Spaces: Public Support for Farmland Protection." American Farmland Trust Center for Agriculture in the Environment Working Paper CAE/WP99-1, 1999.

Krutilla, K. "Environmental Regulation in an Open Economy." Journal of Environmental Economics and Management 20(1991): 127-42.

Lindland, J. "Non-Trade Concerns in a Multifunctional Agriculture." OECD Workshop on Emerging Trade Issues in Agriculture, Paris 26-27 October, 1998 http://www.oecd.org/agr/trade/

Lopez, R.A., F.A. Shah, and M.A. Altobello. "Amenity Benefits and the Optimal Allocation of Land.” Land Economics 70(1994): 53-62.

Mas-Collel, A., M.D. Whinston, and J.R. Green. Microeconomic Theory. New York: Oxford University Press, 1995.

Nersten, N. K., and S. S. Prestegard. "Non-Trade Concerns in the WTO Negotiations" Paper presented at the International Agricultural Trade Research Consortium Annual Meeting, Florida December 1998. 
Office of Management and Budget, Executive Office of the President of the United States. Budget of the United States Government, Fiscal Year 2000.

Ollikainen, M. "On Optimal AgriEnvironmental Policy: A Public Finance View." Paper presented at the IXth European Association of Agricultural Economists Congress, Warsaw Poland, August 1999.

Organization for Economic Cooperation and Development (OECD) (1997a). Environmental Benefits from Agriculture: Issues and Policies. The Helsinki Seminar. Paris: OECD, 1997.

(1997b). Helsinki Seminar on Environmental Benefits from Agriculture: Country Case Studies. GD(97)110. Paris: OECD, 1997.

Norwegian Royal Ministry of Agriculture. "Non-Trade Concerns in a Multifunctional Agriculture: Implications for Agricultural Policy and the Multilateral Trading System." June 1998.

Pimentel, D., H. Acquay, M. Biltonen, P. Rice, M. Silva, J. Nelson, J. Lipner, S. Giordano, A. Horowitz, and M. D'Amore. "Environmental and Economic Costs of Pesticide Use." BioSceince 42(1992): 750-60.

Poe, G.L “ 'Maximizing the Environmental Benefits per Dollar Expended': An Economic Interpretation and Review of Agricultural Environmental Benefits and Costs." Society \& Natural Resources 12(1999): 571-98.

"Valuation of Groundwater Quality Using a Contingent Valuation Damage Function Approach.” Water Resources Research 34(1998): 3627-33.

. "Extra-Market Values and Conflicting Agricultural Environmental Policies." Choices. Third Quarter 1997: 4-8.

Powell, J.R. "The Value of Groundwater Protection: Measurement of Willingness-to-Pay Information and its Utilization by Local Government Decision-Makers. Unpublished Ph.D. Dissertation, Department of Agricultural Economics, Cornell University, Ithaca, NY, 1990.

Runge, C. F. "Beyond the Green Box: A Conceptual Framework for Agricultural Trade and the Environment" Working Paper WP99-1, Center for International Food and Agricultural Policy, University of Minnesota April 1999.

"Emerging Issues in Agricultural Trade and the Environment" OECD Workshop on Emerging Trade Issues in Agriculture, Paris 26-27 October, 1998 http://www.oecd.org/agr/trade/ 
Schamel, G. and H. de Gorter. "Trade and the Environment: Domestic versus Global Perspectives." Humboldt-Universitat Zu Berlin, Wirtscafts- und Sozialwissenschaften an der Landwirtschaftlich-Gartnerischen Fakultat, Working Paper Nr. 34/97, 1997.

Schultz, S.D. and B.E. Lindsay. "The Willingness to Pay for Groundwater Protection." Water Resources Research 26(1990): 1869-75.

Siebert, H., J. Eichberger, R. Gronych, and R. Pethig. Trade and Environment: A Theoretical Enquiry. Amsterdam: Elsevier, 1980.

Whalley, J. "Environmental Considerations in a New Multilateral Agricultural Negotiations, and Associated Developing Country Concerns." Paper presented at the Conference on Agriculture and the New Trade Agenda in the WTO 2000 Negotiations, Geneva, Switzerland, October 1-2, 1999.

World Trade Organization (WTO) (1999a). "Environmental Effects of Trade Liberalization in the Agricultural Sector." Submission by Norway to the Committee on Trade and the Environment. WT/CTE/W/100, January 1999. http://www.wto.org/wto/ddf/ep/public.html

(1999b). "Preparations for the 1999 Ministerial Conference: Negotiations on Agriculture." Communication from Japan to the General Council. WT/GC/W/220, June 1999. http://www.wto.org/wto/ddf/ep/public.html

(1999c). "Preparations for the 1999 Ministerial Conference: Negotiations on Agriculture." Communication from Switzerland to the General Council. WT/GC/W/261, July 1999. http://www.wto.org/wto/ddf/ep/public.html

. "Non Trade Concerns in the Next Agricultural Negotiations." Submission by Argentina to the Committee on Trade and Environment. WT/CTE/W/97, August 1998. http://www.wto.org/wto/ddf/ep/public.html 